\title{
Study on PVDF-HFP/PMMA/CMC Blended Polymer as Membrane for Lithium-Ion Batteries
}

\author{
Huabin Guo ${ }^{1}$, Shengwen Zhong ${ }^{1, *}$, Liping Chen ${ }^{2}$, Guanghuai Peng ${ }^{2}$, Fang Fang Wang ${ }^{1}$, \\ TingTing $\mathrm{Yan}^{1}$, Jingwei $\mathrm{Hu}^{1}$ \\ ${ }^{1}$ School of Materials Science and Engineering, Jiangxi University of Sciences and Technology, \\ Ganzhou 341000, China. \\ ${ }^{2}$ School of Chemistry and Chemical Engineering, Gannan Normal University, Ganzhou 341000, \\ China. \\ *E-mail: zhongshw@126.com
}

Received: 21 October 2021 / Accepted: 23 November 2021 / Published: 6 December 2021

\begin{abstract}
The PVDF-HFP/PMMA/CMC blended solid polymer prepared by solvent volatilization method with PVDF-HFP as host polymer matrix and PVDF-HFP/PMMA as blended membrane and then PVDFHFP/PMMA modified by coating carboxymethyl cellulose(CMC) was introduced in this study to overcome the shortcomings of organic solvent-based liquid electrolyte in lithium-ion batteries. The synthesized copolymers were characterized by FTIR, TGA, XRD, and the results show that PMMA can be well dispersed in PVDF-HFP solution and the addition of CMC can reduce the crystallinity of the polymer membrane, which accelerates the movement of the polymer chain segments and improves the migration rate of lithium-ions. The electrical conductivity of the gel polymer was investigated by AC impedance, and the room temperature ionic conductivity of the gel polymer was up to the order of $10^{-3}$ $\mathrm{S} \cdot \mathrm{cm}^{-1}$, and the electrochemical stability window was $4.8 \mathrm{~V}$. The polymer lithium-ion battery assembled with $\mathrm{LiCoO}_{2}$ as cathode and lithium sheet as anode has good cycle stability. The lithium metal polymer cell delivered discharge specific capacity with $162.52 \mathrm{mAh}^{-1}{ }^{-1}$ at the first cycle, and these properties indicate that the modified gel polymer has applicative prospect in polymer lithium-ion batteries.
\end{abstract}

Keywords: Lithium-ion batteries, Gel polymer, Carboxymethyl cellulose

\section{$\underline{\text { FULL TEXT }}$}

(C) 2022 The Authors. Published by ESG (www.electrochemsci.org). This article is an open access article distributed under the terms and conditions of the Creative Commons Attribution license (http://creativecommons.org/licenses/by/4.0/). 